Dermatology 2007;215:360

DOI: 10.1159/000107633

\section{SACRAL Syndrome}

Beth Drolet ${ }^{\text {a }}$ Maria Garzon ${ }^{\text {b }}$

aPediatric Dermatology, Medical College of Wisconsin, Dermatology and Birthmarks and Vascular Anomalies, Children's Hospital of Wisconsin, Milwaukee, Wisc., and ${ }^{\mathrm{b}}$ Clinical Dermatology and Clinical Pediatrics, Columbia University, New York, N.Y., USA

Key Words

Spinal dysraphism $\cdot$ Angioma

We read the article SACRAL Syndrome: Spinal Dysraphism, Anogenital, Cutaneous, Renal and Urologic Anomalies, Associated with an Angioma of Lumbosacral Localization [1]. The association between cutaneous hemangiomas in the lumbosacral area and underlying developmental anomalies was first reported by Goldberg and Esterly over 20 years ago and the acronym PELVIS was recently published to emphasize this well-recognized association $[2,3]$. We believe the authors highlight the importance of this association; however, they have underemphasized the importance of the location of the cutaneous hemangioma and associated anomalies.

In the 'Methods' section, the authors state that they retrospectively reviewed all hemangiomas in the 'perineal region' not the lumbosacral region. The anatomic definition of the perineum is the region of the body between the anus and the opening of the urethra. This is a very important distinction as the perineum is derived from a separate embryonic unit than the lumbosacral region. Knowledge of developmental origin of the skin in these regions is essential and may help predict the risk of underlying anomalies and dictate the need for screening [4]. In this study, every patient with associated spinal dysraphism had hemangioma involving the skin of the midline lumbosacral region. So in essence the only infants that had occult (not obvious by physical examination) abnormalities had hemangiomas that involved the lumbosacral region of the skin. The skin overlying the lumbosacral region has an intimate developmental relationship with the neural tube, whereas sacral, coccegeal, and perineal skin does not. Cutaneous dimples over the lumbosacral region are often indicative of underlying spinal dysraphism whereas isolated anorectal, perineal, and sacral dimples are not associated with dysraphism. Hemangiomas in the perineal region are most often seen as an isolated finding and infrequently they may occur with obvious anogenital anomalies, as described in case number 1 . The authors conclude that 4/9 'midline' lesions had associated anomalies. The term 'midline' is used loosely, without specifying midline perineum, midline sacrum, or midline lumbar. A reader may be lead to believe all midline lesions need a screening MRI. In practice most practitioners do not screen all patients with perineal hemangiomas as the associated malformations are often easily visualized [5]. In contrast hemangiomas of the lumbosacral region are frequently markers of occult spinal anomalies that are often asymptomatic in young children and may result in the permanent neurologic deficits (tethered cord syndrome). Although the authors do not explicitly recommend imaging for all perineal hemangiomas, they fail to emphasize the importance of lumbosacral location in the text of the article.

\section{References}

1 Stockman A, Boralevi F, Taieb A, Leaute-Labreze C: SACRAL syndrome: spinal dysraphism, anogenital, cutaneous, renal and urologic anomalies, associated with an angioma of lumbosacral localization. Dermatology 2007;214:40-45.

2 Goldberg NS, Hebert AA, Esterly NB: Sacral hemangioma and multiple congenital abnormalities. Arch Dermatol 1986;120:684-687.

3 Girard C, Bigorre M, Guillot B, Bessis D: PELVIS Syndrome. Arch Dermatol 2006; 142:884-888.

4 Drolet BA Esterly NB, Frieden IJ: Hemangiomas of Infancy. N Engl J Med 1999;341:173-181.

5 Drolet BA, Boudreau C: When good is not good enough: the predictive value of cutaneous lesions of the lumbosacral region for occult spinal dysraphism. Arch Dermatol 2004;140:1153-1155.

\section{Beth Drolet}

Pediatric Dermatology, Froedert East, 9200 West Wiconsin Ave Milwaukee, WI 53211 (USA)

Tel. +1 414805 9859, Fax +1 414258 8085, E-Mail drolet@mcw.edu

and

Maria C. Garzon, MD

Associate Professor of Clinical Dermatology and Clinical Pediatrics Columbia University, New York, NY (USA)

E-Mail Mcg2@columbia.edu

\author{
Dermatology 2007;215:360-361 \\ DOI: 10.1159/000107634
}

\section{Reply}

\section{Christine Labrèze}

Unité Dermatologie Pédiatrique, Hôpital Pellegrin-Enfants, Bordeaux, France

\section{Key Words}

Infantile hemangioma $\cdot \mathrm{SACRAL} \cdot \mathrm{PHACES}$ syndrome $\cdot$ Spinal dysraphism

We read with interest the comments by Drolet and Garzon concerning our paper entitled SACRAL syndrome. We agree that the association between cutaneous hemangioma of the lumbosacral area and occult dysraphism was first reported by Golberg and Esterly [1], and this paper was referenced as number 6 in our article. However, concerning the 2006 paper published by our French colleagues in the Archives of Dermatology [2], where they proposed the acronym PELVIS, we want to clarify that this work was not yet published when our paper was submitted. In addition, the SACRAL acronym was proposed by us more than 3 years ago 
at the 7th Congress of the European Society for Pediatric Dermatology in Barcelona in 2002 and at the Journées Dermatologiques de Paris in December 2003 [3].

Drolet and Garzon are right about the importance of the lumbosacral location of the hemangioma as a marker of occult spinal dysraphism, which we did not want to underemphasize, as they state in their letter. We indeed emphasized this location in the proposed acronym, with S standing for spinal dysraphism and $\mathrm{A}$ and L standing for angioma of lumbosacral localization. Despite a different embryonic origin of these two regions, perineum and lumbosacral area, an hemangioma can involve both areas, and the key message is that the clinician should be aware of all possible significant associated anomalies when examining a baby with an hemangioma of the 'napkin area'. Eventually, future prospective studies, as already performed for the PHACES syndrome [4], will probably better delineate the SACRAL/PELVIS syndromes.
References

1 Goldberg NS, Hebert AA, Esterly NB: Sacral hemangiomas and multiple congenital abnormalities. Arch Dermatol 1986;122:684-687.

2 Girard C, Bigorre M, Guillot B, Bessis D: PELVIS syndrome. Arch Dermatol 2006;142:884-888.

3 Stockman A, Boralevi F, Taïeb A, Léauté-Labrèze C: Définition d'un nouvel acronyme pour les hémangiomes du siège: SACRAL. Ann Dermatol Vénéréol 2003;130:4S172.

4 Metry DW, Haggstrom AN, Drolet BA, Baselga E, Chamlin S, Garzon $M$, et al: A prospective study of PHACE syndrome in infantile hemangiomas: demographic features, clinical findings and complications. Am J Med Genet [A] 2006;140:975-986.

Dr. Christine Labrèze

Unité Dermatologie Pédiatrique, Hôpital Pellegrin-Enfants

Place Amélie Raba-Leon, FR-33076 Bordeaux Cedex (France)

E-Mail christine.labreze@chu-bordeaux.fr 